\title{
SOME MORPHOLOGICAL CHANGES OCCURRING IN EPITHELIAL CELLS AS A RESULT OF DISEASE.
}

\author{
By D'Arcy Power, M.A., M.B. Oxon., F.R.C.S. Eng., Demonstrator of \\ Surgery at St. Bartholomew's Hospital and Lecturer on Histology \\ at the Royal Veterinary College. \\ From the Conjoint Laboratories of the Royal Colleges of Physicians (Lond.) \\ and Surgeons (Eng.). \\ Pifate VII.
}

Some years ago I started in quest of the origin of cancer, but it soon became obvious that a more useful, if more humble, work must first be performed, for it was necessary to conduct a series of control experiments to ascertain what changes occurred as a result of irritation and disease in the mammalian cell.

Bearing in mind the original purpose of my work, I have confined my attention to the epithelial cells in mammalia, though I know full well that the mesoblastic connective tissues present an equally interesting field of observation, and one which is of no less importance, for we know as little of the stroma of cancer as of its epithelial elements. Further, I have limited myself to the morphological changes taking place in degenerate cells, and, working upon purely morphological lines, I first kept the mucous membranes of the vagina and of the conjunctiva of rabbits and guinea-pigs in a state of chronic irritation for long periods of time. I thus became familiar with the appearances presented by cells which have been artificially irritated, and some of these appearances I have depicted in previous papers. ${ }^{1}$ My present purpose is to show how close is the resemblance between some of the changes thus artificially produced and those which may be found as a result of disease in the epithelial cells of the human being.

The excellent work upon the structure and development of the placenta which has recently been issued from the Owens College, Manchester, by Professor Young and Dr. Arthur Robinson, ${ }^{2}$ shows how

${ }^{1}$ Brit. Med. Joumn., London, 1893, vol. ii. p. 830 ; Journ. Path. and Bacteriol., Edin. and London, 1894, vol, iii. p. 124.

${ }^{2}$ Brit. Med. Journ., London, 1895, vol. ii. p. 1339. 
important a part is played by the degeneration of cells in the developmental processes both in epiblastic and mesoblastic structures. Professor Young and Dr. Robinson have kindly allowed me to examine their preparations at my leisure, and although the tissues are not prepared exactly in the same manner as my own, it is obvious that many of the changes which they have observed are identical with those seen in irritated and diseased tissues.

The cells depicted in the annexed figures were obtained from an intra-cystic growth of the mammary gland, sent to me by my friend Dr. Humphrey Rolleston, who had noticed that the epithelium presented many appearances of degeneration. The tissue was hardened, cut, and stained in exactly the same manner as has been already described,' for unless identical methods are employed, it is impossible to compare the results obtained. The photomicrographs, with the exception of Figs. 7 and 8 on Plate VII. were taken under a uniform magnification of 600 diameters.

A general view of the tissue, magnified about 90 diameters, shows it to be a fibrous growth, which here and there contains cysts. The bulk of the fibrous tissue is very dense, it is not vascular, and it does not contain many nuclei. It becomes better supplied with blood vessels as it approaches the wall of a cyst, for it is more actively growing at these points, and it is then infiltrated by numerous small round cells of indifferent tissue. This zone of inflamed fibrous tissue projects into the cavity of the cyst in nipple-like processes, and each process, as well as the cyst wall itself, is covered with epithelium.

The tumour was removed May 22, 1894, by $\mathrm{Mr}$. W. H. Bennett from the left breast of a woman aged 47 , where it had been growing for two years. The nipple was not retracted, there was no history of any blood-stained discharge, and histologically it was innocent, yet it recurred in November 1894. This, however, is not unusual, as we know that the clinical course followed by many such intra-cystic growths in the mammary gland is locally malignant, for it invades the surrounding tissues, fills up the cysts, and eventually fungates. An examination of the epithelium shows that the component cells are large and spheroidal, fitting closely into each other, and often arranged in more than one layer. The whole epithelium is infiltrated with small round cells, derived from the inflamed connective tissue beneath it. The individual epithelial cells are healthy in many parts, but in others they have undergone very marked changes. These changes in some instances are in the direction of complete cell disintegration, whilst in others they are in the direction of a "colloid" degeneration.

A minute examination of the epithelial cells under a Leitz No. 1 ocular and Swift's $\frac{1}{12}$ th in. oil-immersion objective shows that the degenerative changes affect the cell-nucleus as well as the cell-sub-

1.Journ. Path. and Bacteriol., Edin. and London, 1894, vol. iii. p. 126. 
stance. Both parts of the cell are equally affected in some cases, but usually one part is more affected than the other. The degeneration varies, too, in amount from the very slightest extent to complete disintegration.

The simplest changes are to be seen in Plate VI. Fig. 1, where a large spheroidal cell contains a partially digested leucocyte, which is itself provided with two nuclei. The substance of the epithelial cell has partially shrunk away from its periphery, and such unequal shrinking of the cells is not at all uncommon in degenerating epithelium. The outer portion of the cell and the periphery of the nucleus present a number of spaces or dots which stain less deeply than the rest of the cell-substance. Some of the other cells in this field of the microscope present indications of similar degenerative changes, whilst in the cell lying directly above the central one, there are two circular patches of degeneration in the cell-substance.

Plate VII. Fig. 2 presents somewhat similar changes, but they are more advanced and are clearly in the same direction of "colloid" change. The nuclei of the cells appear to be normal, but in the central cell the protoplasm is degenerating, whilst its neighbour exhibits a remarkably well-defined patch. These circumseribed patches are very numerous in all the sections of the tumour. Each is spherical, and, as they only stain lightly, the centre appears to be darker than the outer portion when they are seen in optical section. Similar circular patches of degeneration are of common occurrence in epithelium which has been artificially irritated. I have depicted several varieties of this form of change in a previous paper. ${ }^{1}$ It should be borne in mind, however, that all the circular bodies found in diseased or irritated epithelium are not necessarily due to "colloid" degeneration in parts of the cell-substance, for an entire cell may degenerate in such a manner as to leave a more or less circular central mass, whilst the outline is not so clean-cut as in the previous form. An example of so complete a cellular change is seen in Plate VII. Fig. 3, where the indented outline is very conspicuous. This appearance is almost identical with that represented in Plate IX. Fig. 8 in the third volume of this Journal. The change is a complete one, and in neither case does the central mass represent the original nucleus of the cell.

Plate VII. Fig. 4 shows an intranuclear degeneration in a very complete form. The affected nuclei are swollen and circular, whilst the cell-substance has shrunk away from them in some of the cells. The change is best marked in the nuclei, but it is not confined to them, for to the left of the centre of the section is a minute circular mass of degeneration, like that seen on a larger scale in Plate VII. Fig. 2.

Plate VII. Fig. 5, shows changes in many respects similar to those

${ }^{1}$ Journ. Path. and Bacteriol., Edin. and London, 1894, vol. iii. Plate VIII. Figs. 3, 4, and 6 , and Plate IX. Fig. 7. 
seen in Fig. 4. The intranuclear substance is more coarsely granular, whilst the cell shrinkage is so irregular that a considerable space is left between two adjoining cells.

Plate VII. Fig. 6 shows that the intranuclear shrinkage may be almost regular in its irregularity, for it has led to the formation of a festooned figure within a very sharply defined outline. The degenerate portion stains more deeply than the cell-substance, and there is again evidence of unequal shrinkage. The cell beneath that which contains the festoon presents similar changes, but they are not so far advanced.

Plate VII. Figs. 7, 8, and 9 show degenerate changes of a somewhat different type, though they still follow the broad lines exhibited by the previous figures. They are "colloidal" changes, taking place either in the cell-substance or in the nuclei, but the changes are upon a much larger scale than in those already shown. The degeneration has affected neighbouring cells, and the cell-substance seems to have suffered more than the nuclei. The nuclei consequently have been pressed out of shape.

Plate VII. Fig. 7 shows the symmetry of the changes affecting this portion of the epithelium. Two neighbouring cells have become so far fused that their nuclei form a single crescentic mass, but the cell-substance is still distinct, and is separated by a well-defined line. In each case, however, it has undergone a very marked alteration. Similar changes, but not so well marked, are seen in other parts of the section.

Plate VII. Fig. 8, too, shows changes which are in many respects similar to those seen in Fig. 7, though there is no evidence that any of the cells have fused. The degeneration of the cell at the top left-hand corner of the figure is very complete, and appears to be similar to the appearance elsewhere represented, ${ }^{1}$ except that in this case the degenerative change is further advanced.

Plate VII. Fig. 9 is from the same part of the section as Figs. 7 and 8 , but the focus is different, and it is under a slightly lower magnification. It shows the complete disappearance of the nucleus which has taken place in the four-sided cell at the top left-hand side of the figure.

Plate VII. Fig. 10 shows a variety of interesting appearances in the cells, which have been so arranged accidentally as to show in an almost diagrammatic manner a series of cells ranging from a state of health to that of extreme degeneration. Two cells are seen lying side by side in the lower and right-hand portion of the figure. The nucleus of the one is long and curved, so that it partially embraces that of the other which is more rounded. The two nuclei are separated from each other by a small amount of cell-substance. The protoplasm of the cells is normal, but the nuclei present slight traces of punctate degeneration. This arrangement of two neighbouring cells is not

${ }^{1}$ Journ. Path. and Bacteriol., Edin. and London, 1894, vol. iii. Plate IX. Fig. 10. 
uncommon in epithelia, and it is frequently met with in sections of squamous epithelioma, where it seems to be a fertile cause of cellfusion.

The epithelial cell at the top of the section has undergone a form of degeneration, which is more advanced in the deeper than in the more superficial portion of its cell-substance. The protoplasm along its outer border is normal, so far as microscopical examination shows, but that lying beneath the nucleus of the cell contains many circular drops of "colloid" substance. If these drops fused together, they would produce the appearance seen in the cell lying below, and to the right of that just described. The protoplasmic substance in this cell has been replaced by a large drop of "colloid" material, which has pressed aside the nucleus, and has forced it to assume a crescentic shape.

The circular mass situated upon the right side of the figure is the result of similar changes carried almost to their extreme limit. Two cells are involved in the degeneration, and they probably bore the same relation to each other as that seen in the pair lying a little lower down in the section which has already been described. The nuclei of the two cells have become pressed outwards by the degeneration of the cell-substance, until they are reduced to the two crescentic outlines which partly bound the mass.

Plate VII. Fig. 11 shows that the changes do not always begin eccentrically, forcing the nucleus aside and pressing it out of shape. They may begin concentrically or tolerably evenly in all parts of the cell-substance. The cell in such cases increases in size, and the nucleus soon becomes indistinguishable. The saprophytic appearance seen in the degenerate cell in the centre of the figure is due to some alteration in the chromatin filaments of the cell.

The whole of the epithelial changes described in this paper appear to be in the direction of a single form of degeneration, which must be called provisionally "colloid." It is the conversion of one or more cells, either partially or as a whole, into a viscid substance. The change begins by the formation of one or of a large number of globules, which are deposited in the cell-substance or in the nucleus. "The globules either remain separate, or they run together to form larger globules, to the great and lasting detriment of the cell, which may be thus completely destroyed. I term this substance "colloidal" for the sake of convenience, but we know absolutely nothing of its chemical nature, and it would not be in the least surprising to find that it consisted of several distinct compounds. The chemical nature of the substances formed by degenerating epithelium would be an excellent subject for investigation. It is one, also, from which we might expect valuable results in connection with the changes occurring in cancer. We have much to learn in this field, for, at present, no 
competent investigator has turned his attention to the micro-chemistry of the epithelial tissues, yet there is but little doubt, as Sir William Broadbent says, that chemistry must ultimately form the link between physiology, pathology, and therapeutics.

\section{DESCRIPTION OF PLATE VII.}

FIG. 1.-Epithelium from an intra-cystic manmary tumour. The cell in the centre of the field shows irregular shrinkage of its cell-substance, which contains a leucocyte. The nucleus of the cell presents numerous points of degeneration, which are more marked at the margin than at the centre. Foa, Ehrlich's hæmatoxylin. $(\times 600$.

FIG. 2,-Epithelium from the same tumour. There is some degenerative change in the cell-substance of one of the cells, whilst its neighbour presents a well-defined circular patch with a darker central portion. $(\times 600$.

FIG. 3.-The very degenerate epithelium contains an oval body with an irregular outline and a more deeply staining central portion. ( $\times 600$.

Fic. 4.-The nuclei throughout the section have undergone degenerative changes. They are nearly all swollen, and the cell-substance in several cases has shrunk away from them. There is a minute point of circular degeneration at one spot near the centre of the figure. $(\times 600$.

FIG. 5.-The nuclei in this section are more coarsely granular than in the previous one, the changes are otherwise the same. One of the cells shows very unequal shrinkage. ( $\times 600$.

FIG. 6 -The nuclei are again chiefly affected, and one of them presents a festooned arrangement with a well-defined circular outline. $(\times 600$.

Fig. 7.-The degenerative changes are symmetrical, and are confined to the cell-substance. $(\times 700$.

FrG. 8.- Similar changes from a part of the section closely adjoining that represented in Fig. 8. The stress of the degeneration has again fallen upon the cellsubstance rather than upon the nuclei. $(\times 700$.

Fig. 9. - Various degenerative changes in the substance of the epithelial cells. $(\times 600$.

FIG. 10.-The cells in this figure show how the degenerative changes, commencing eccentrically in the cell-substance, may lead to the formation of large degenerate masses in the manner described in the text. $(\times 600$.

FIg. 11.-An epithelial cell which has become greatly enlarged as a result of degenerative changes occurring in its centre. ( $\times 600$.) 


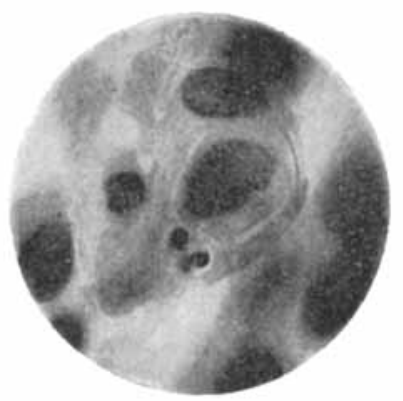

Fig. 1.

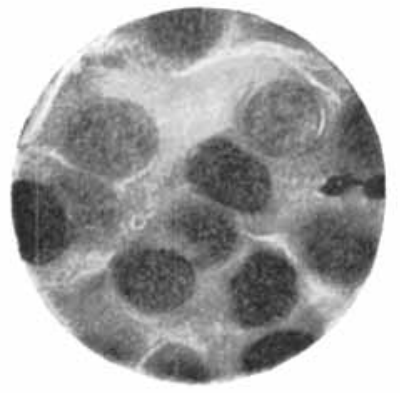

Fig. 4.

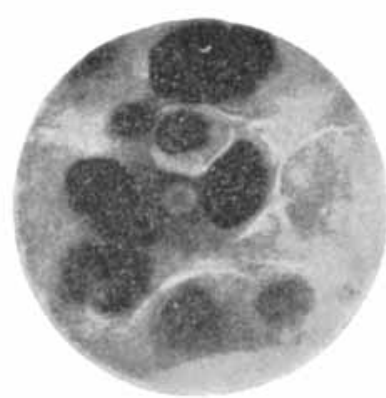

FIG. 2.

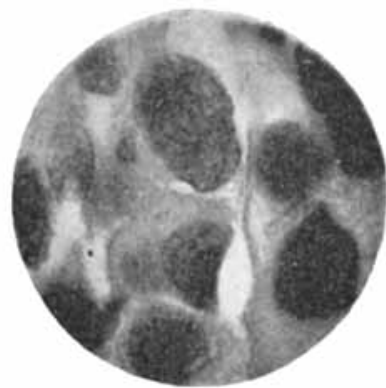

Fig. 5.

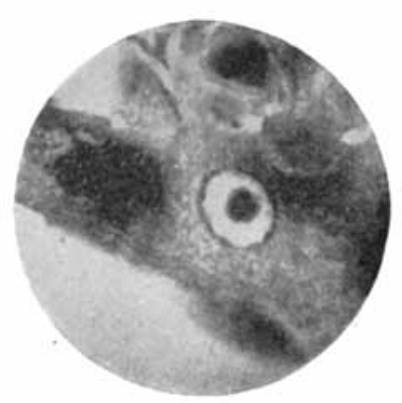

Fig. 3.

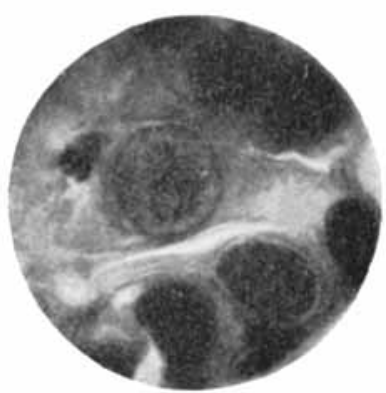

Fig. 6.

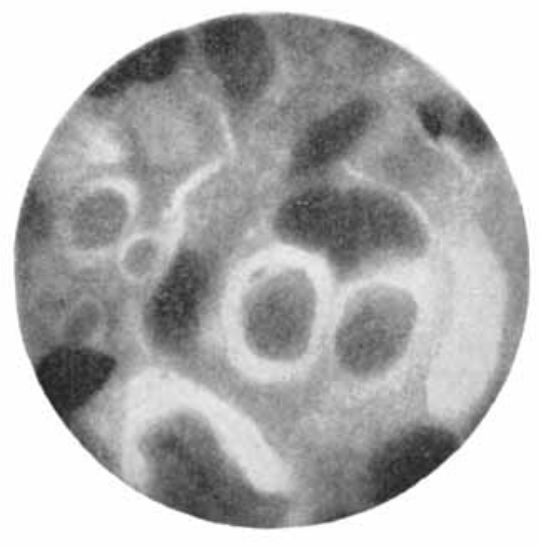

Fig. 7.

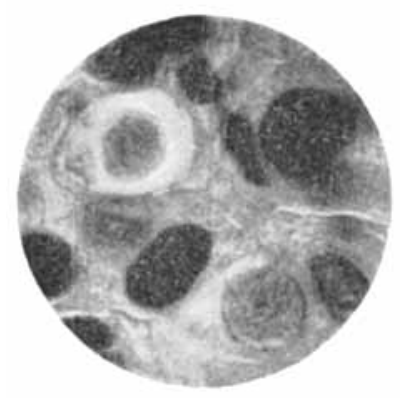

Fig. 8 .

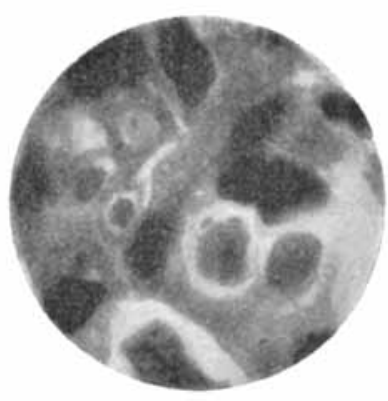

Fig. 9.

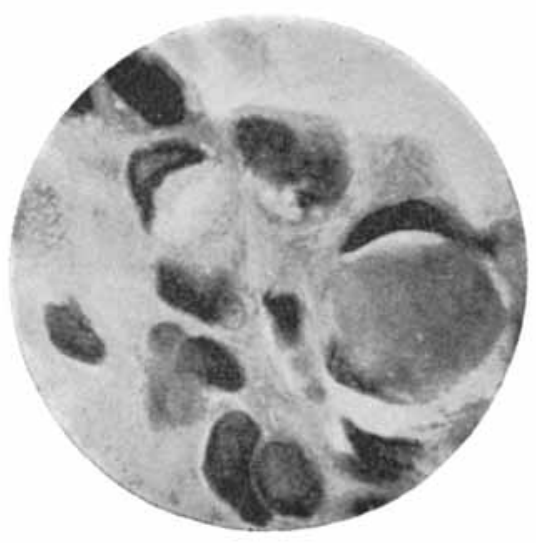

Fig. 10.

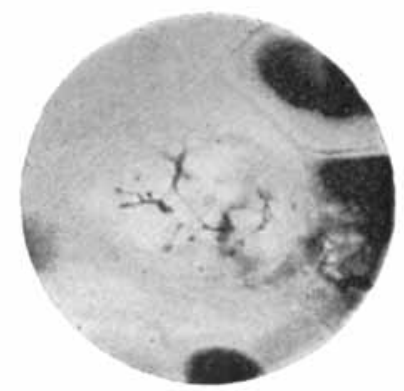

Fig. 11. 


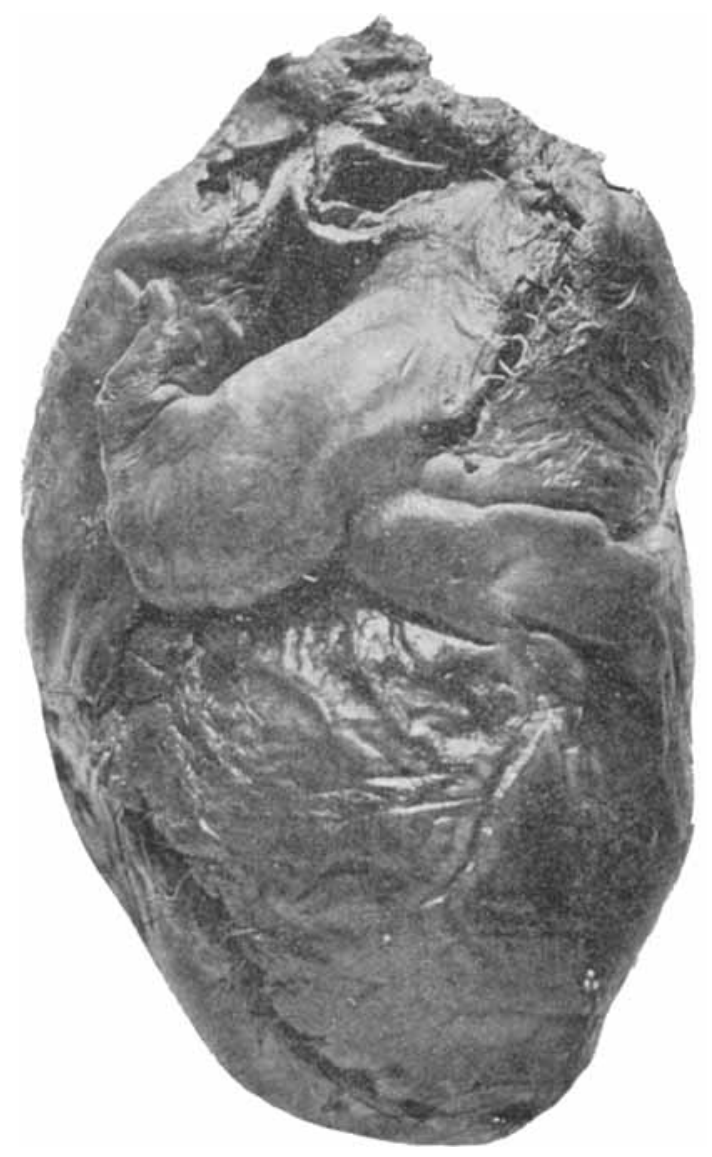

